\title{
Indications for Surgical Removal of the Eye in Lafia.
}

\author{
O.O. Adenuga $F W A C S^{l}$, P.D. Wade $F M C O p h^{l}$, R.O. Ewuga $M B B S^{2}$, T.N. Abuba \\ $M B B S^{3}$
}

${ }^{1}$ Consultant Ophthalmologist, Department of Ophthalmology, Jos University Teaching Hospital, Jos.

${ }^{2}$ Registrar, Department of Ophthalmology, Dalhatu Araf Specialist Hospital, Lafia.

${ }^{3}$ Senior Registrar, Department of Family Medicine, Dalhatu Araf Specialist Hospital, Lafia.

Correspondence; OOAdenuga

E-mail; Korexmed@yahoo.com

\begin{abstract}
Objective; To determine the indications for surgical removal of the eye in Lafia, Nasarawa State in north central Nigeria.

Method; Clinical records of patients who had undergone surgical removal of the eye over a 1 year period between March 2008 and February 2009 were reviewed retrospectively. The patients' demographic data and clinical indications for removal were obtained and analysed.

Results: 12 patients had an eye removed during the period with 4 (33\%) of these being children. Two-thirds of the patients were males. Severe ocular trauma was the commonest reason for the removal of an eye accounting for 33\% of the cases. This was followed by staphyloma which accounted for $25 \%$ of the cases. Measles infection was however an underlying factor in $41 \%$ of the eyes removed. Evisceration was the most common procedure performed in $83 \%$ of cases.

Conclusion; Most of the indications for surgical removal of the eye were avoidable with measles being an underlying factor in $41 \%$ of the cases. Urgent measures therefore need to be taken by the state Ministry of health to improve primary eye care in the state.
\end{abstract}

\section{Introduction}

The surgical removal of the eye is an unfortunate end to certain ocular morbidities ${ }^{1}$. Recommending the procedure is one of the most difficult therapeutic decisions in ophthalmology and is usually a last form of treatment a surgeon resorts to. There are various indications for surgical removal of the eye and these include; malignant intraocular tumours not amenable to alternative modes of therapy, an unsightly or painful blind eye, a badly traumatized eye, and severe intraocular infection not amenable to medical treatment ${ }^{2}$. A badly traumatized eye has been found to be the commonest indication for removal of the eye by several authors in our environment ${ }^{1,3,4,5}$.

The surgical removal of the eye can be done by enucleation, evisceration or exenteration ${ }^{3}$. Enucleation is one of the oldest procedures in ophthalmic surgery ${ }^{6}$ and it involves removal of the whole eyeball by cutting the six extraocular muscles and transecting the optic nerve ${ }^{2}$. Evisceration involves removing the contents of the eye leaving only the scleral shell while in exenteration the entire orbital contents, including the periorbita, are surgically removed ${ }^{2}$.
We have reviewed the reasons for surgical removal of the eye in Lafia over a 1yr period. Most of the similar studies in this environment have shown that majority of the indications for removal of the eye was avoidable $\mathrm{e}^{3,4,5}$. We therefore believe our findings will not only reveal some of the possible causes of blindness in Lafia but will also reveal areas of primary eye care that need to be improved upon by the state ministry of health.

\section{Materials and Methods}

This is a retrospective study carried out at the Department of Ophthalmology of the Dalhatu Araf Specialist Hospital in Lafia, Nasarawa State. Clinical records of patients who had surgical removal of the eye over a 1 year period from March 2008 to February 2009 were reviewed. Data on age, sex, diagnoses and type of surgical procedure were obtained. Data analysis was done using Epi-info 2002 revision 1 for simple percentages.

\section{Results}

348 surgeries were performed over this period with $12(3.4 \%)$ of these being surgical removal of the eye. Age range of the patients was 1.5-80 years, mean $31.25 y r s$. All the children were under 5 years 
of age with a mean of 2 yrs (range 1.5-3yrs). Age range of the adults was 26-80yrs with a mean of 54.6years. Males accounted for two thirds of the patients (figure 1) while $33 \%$ of the patients were children. Evisceration was the commonest procedure performed in $83 \%$ of cases.

Trauma was the commonest indication for removal of the eye (33\%) and $75 \%$ of these patients were males. This was followed by staphyloma in 3 $(25 \%)$ persons. Previous measles infection was a predisposing factor in all the cases of staphyloma. Measles infection was also an underlying factor in a case of keratomalacia and in a $45 \mathrm{yrs}$ old man with a spontaneous rupture of a blind eye. Panophthalmitis accounted for $16.7 \%$ while retinoblastoma accounted for $8.3 \%$ of the indications (table 1).

Trauma was the leading indication for removal of the eye in adults while measles infection in $75 \%$ of the children led to ocular complications necessitating surgical removal of the eye.

\section{Figure 1: Sex distribution of the patients}

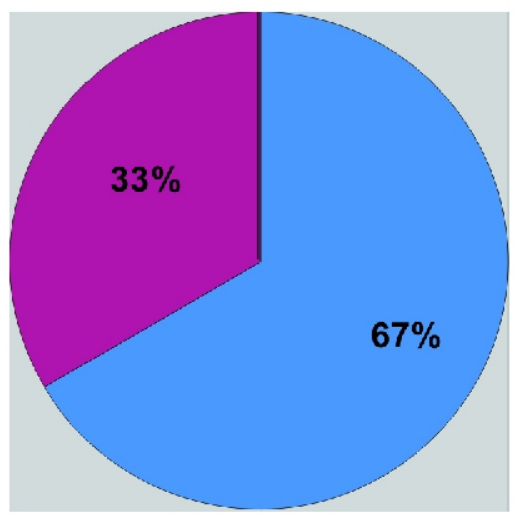

$\square$ Males

Females

Table 1; Ind ications for surgery

\begin{tabular}{ll} 
Indication & No $(\%)$ \\
\hline Trauma & $4(33.3)$ \\
Staphyloma & $3(25)$ \\
Panophthalmitis & $2(16.6)$ \\
Spontaneous rupture & $1(8.3)$ \\
of a blind eye & \\
Keratomalacia & $1(8.3)$ \\
Retinoblastoma & $1(8.3)$ \\
Total & $\mathbf{1 2 ( 1 0 0 )}$ \\
\hline
\end{tabular}

\section{Discussion}

Males accounted for the majority of cases in this review. This is comparable to the findings in several other similar studies, ${ }^{1,4}$. Enock et al however reported an equal proportion of both sexes in their series ${ }^{5}$. Irreparable globe trauma was the commonest indication for surgical removal of the eye in this review with most of these patients being males. This compares favourably with findings by other authors in Jos $^{3}$, Ile-Ife ${ }^{1}$, Enugu ${ }^{4}$ and Irrua ${ }^{5}$. Ocular trauma has been shown to occur more in active young men.

Staphyloma was the second leading indication for removal of the eye in this review. This finding is similar to what was reported by Dawodu and Faal in the Gambia ${ }^{7}$. In the reports from $\mathrm{Jos}^{3}$ and Enugu ${ }^{4}$ however, intractable infection was the next major indication after trauma. All the cases of staphyloma were preceded by measles infection. Two other cases in this review were also associated with measles infection. Measles was thus as an underlying factor in about $42 \%$ of the eyes removed and in $75 \%$ of the cases in the paediatric age group. This is rather unfortunate as measles is a preventable disease and it shows a failure of primary health care in Nasarawa State. In the first quarter of 2008 there was a measles outbreak in Lafia with several children presenting to the eye clinic with ocular complications. We observed during this period that even though immunization services were available they were not being utilized. This indicates that a lot still needs to be done by the state ministry of health in the areas of health education and maternal and child care.

Intractable ocular infection is another avoidable indication for removal of the eye. The cases in this review were preceded by a red eye and the use of traditional eye medication was documented in one of the cases. Traditional eye medication usually causes further damage to a diseased eye by causing a chemical or caustic keratoconjuctivitis or by further contamination of the eye from virulent microorganisms ${ }^{8}$. Health education on the dangers of delayed and inappropriate medication as well as training of community health workers will help in reducing the incidence of avoidable enucleation or evisceration due to intraocular infections.

Retinoblastoma was not a common indication for removal of the eye in the paediatric age group in this study. This contrasts with the series from Ile-Ife ${ }^{1}$ in which retinoblastoma was the commonest indication for removal of the eye in children. This difference may be as a result of the fact that this study was conducted over a shorter period and hence fewer cases were recorded. Also a few other cases of retinoblastoma were seen during the review period but the parents did not consent to removal of the diseased eye. The patients were subsequently lost to follow up. Patients with retinoblastoma 
usually present late in our environment ${ }^{9}$ and at that stage of the disease enucleation or exenteration is usually indicated. Health education during antenatal clinics on the need for mothers to pay attention to the child's eyes as the child grows as well as the importance of seeking early medical attention will encourage early presentation and treatment with alternative forms of therapy that could result in eye and vision salvage. Also community health workers who are usually the first to see most of these patients should be trained to recognize early forms of the disease and to promptly refer when such cases are seen'.

Evisceration was the commonest procedure performed. This is also similar to what was reported in other studies ${ }^{3,4,5}$. This is not unconnected to the indications for surgery as it is easier to eviscerate a badly traumatized eye $\mathrm{e}^{3}$. There is however the risk of sympathetic ophthalmitis developing in the fellow eye ${ }^{10}$. This is fortunately a rare condition and improved medical therapy for uveitis is now available ${ }^{10}$. Also, in cases of intraocular infections the chance of contamination of the orbit and intracranial extension is theoretically reduced with evisceration ${ }^{2,}{ }^{10}$ and motility of the prosthesis is generally better than achieved with enucleation ${ }^{2,10}$.

In conclusion majority of the indications for removal of the eye in this study are avoidable. More therefore needs to be done by the Nasarawa State ministry of health in the area of primary health care particularly as regards to measles prevention and its associated ocular complications.

\section{References}

1. Adeoye AO, Onakpoya $\mathrm{OH}$. Indications for eye removal in Ile-Ife, Nigeria. Afr. J Med. Sci 2007; 36(4): 371-5.

2. Sanford-Smith J. Eye surgery in hot climates. $3^{\text {rd }}$ ed. England: Thorpe Publishing; 2004:290292.

3. Mpyet C, Wade P, Ramyil A. Indications for surgical removal of the eye in adults; a five-year review. Nig. J Med 2008; 17(1): 107-109.

4. Eze BI, Maduka-Okafor FC, Okoye OI, Okoye O. Surgical indications for eye removal in Enugu, South Eastern Nigeria. Nig J. Ophthalmol 2007; 15(2): 44-48.

5. Enock ME, Omoti AE, Fuh UC, Alikah AA. Indications for surgical removal of the eye in Irrua, Nigeria. Nig J. Ophthalmol 2008;16(1): 16-19.

6. Hirst LW. Epibulbar tumours, pterygia, enucleation and evisceration. In: Rice TA, Michels RG, Stark WJ, editors. Rob and Smith's operative surgery; Ophthalmic surgery. $4^{\text {th }}$ ed. London: Butterworths; 1984: 77.

7. Dawodu OA, Faal HB. Enucleation and evisceration in the Gambia. Nig J. Ophthalmol 2000; 8(1): 29-33.

8. Hernandez-Duran LA, Kotiankar S, McGavin M, Gilbert C. Prevention of childhood blindness. Community Eye Health Update CD. London: Institute of community eye health; 2007.

9. Wade PD, Mpyet CD, Alli SK, Langnap L. Problems of managing retinoblastoma in Jos University Teaching Hospital: a 6 year review of cases. Highland Medical Research Journal 2004; 2(1): 49-52.

10. Kersten RC, Codere F, Dailey R, Garrity JA, Nerad JA, Popham JA, Holds JB. Basic and clinical science course, section 7: Orbit, eyelids and lacrimal system. San Francisco: American academy of ophthalmology; 2004: 209-210. 